\title{
The value of England and Wales congenital malformation notification scheme data for epidemiology: male genital tract malformations
}

\author{
A J SWERDLOW ${ }^{1}$ AND D MELZER ${ }^{2}$ \\ From the Office of Population Censuses and Surveys, ${ }^{1}$ Medical Statistics Division, St Catherine's House, 10 \\ Kingsway, London WC2B 6JP and South East Kent Health Authority, ${ }^{2}$ Department of Community Medicine, \\ Ash-Eton, Radnor Park West, Folkestone, Kent CT19 5HL
}

SUMMARY Data from the England and Wales national congenital malformation notification scheme were examined for associations of male genital tract malformations. For some of the malformations comparison of notification rates with the literature suggested gross undernotification. There was also evidence suggesting bias: examination of the relationships of the malformations to birth weight, maternal parity, and maternal age at delivery showed some highly significant trends in risk, most of which were at variance with findings in the literature, and several potential mechanisms for bias could be adduced. Direct investigation is needed, for this and other similar data sets, of the extent and mechanisms of biased undernotification.

Since 1964 the Office of Population Censuses and Surveys (OPCS) has collected data on congenital malformations in England and Wales by a voluntary notification scheme. Notification systems exist also in several other countries, ${ }^{1}$ but that for England and Wales is much the largest population-based scheme reporting to the International Clearing House for Birth Defect Monitoring Schemes, ${ }^{1}$ about 12000 14000 notifications of malformed babies being received annually in recent years. ${ }^{2}$ Data are collected on some potential risk factors for the malformations, and thus OPCS holds an exceptionally large data set for examination of risks.

Appreciable incompleteness and false positive notifications have been demonstrated in the OPCS data, ${ }^{3}$ the extent varying considerably by type of malformation. These defects will matter seriously for examination of risk factors only if they are biased, but the extent of such bias has not been investigated.

The present study used the OPCS data to examine the relationship of several variables to risks of some malformations of male genital tract development not previously examined separately in the England and Wales data. Comparison of the results for some of the malformations (cryptorchidism, hypospadias, and inguinal hernia) with those from previous studies enabled an assessment of whether or not gross bias was likely to exist in the OPCS data; such bias would be of relevance to the use of both the England and
Wales data set and, potentially, other similar data sets elsewhere. The other study malformations (epispadias and hydrocoele) do not appear to have received previous epidemiological study.

\section{Materials and methods}

The OPCS files contain data about congenital malformations noted in the first seven days of life in England and Wales and notified voluntarily by doctors and midwives. Data were extracted about all notifications to OPCS of males born with cryptorchidism in 1981-3, with inguinal hernia in 1974-83, with hydrocoele in 1981-3, with epispadias in 1974-8 and with hypospadias in 1977-8. The years of data included for each malformation except hypospadias were those for which the malformation was separately identifiable on the computer files. For hypospadias, the most commonly notified of the malformations, only the most recent years of separately identifiable data were examined, since these gave a large number of cases and there would have been practical difficulties in extracting further data.

The data were examined in subdivisions by singleton/multiple birth, live/stillbirth, and solitary/ multiple malformation; the risk analyses presented in detail here are for by far the largest homogeneous group-singleton livebirths with solitary malformations. Exactly corresponding denominators 
to calculate notification rates in relation to the risk factors were not available, and therefore the associations were examined by a case-control approach. The controls were based on overall birth registrations in England and Wales and corresponded as far as possible to the case data with respect to sex, live/stillbirth status, etc. For birthweight, the control data were from all male singleton livebirths in England and Wales in 1983; (OPCS unpublished) for mother's age, data were used from all male livebirths in England and Wales for the same years as for the cases; ${ }^{4}$ and for birth order, estimates were used of numbers of previous livebirths to the mother, and for stratified analyses estimates of previous livebirths by maternal age, for all livebirths in England and Wales for the same years as the cases (Werner JB, unpublished). Relative risks of the malformations in relation to the variables examined were estimated by unmatched case-control analysis, ${ }^{5}$ estimating test-based confidence limits, ${ }^{6}$ and testing for significance of linear trends in risk with increasing exposure. ${ }^{7}$ Similar case-control analyses, using the most nearly corresponding control data available, were conducted for risks of all-malformations reported to OPCS in 1974-83 (1977-83 for analysis of birthweight because of data availability), in order to aid consideration of possible biases identified for the study malformations. The all-malformation data were not available subdivided by sex, by plurality, or by whether live or stillborn. Harmonic variation in month of birth of study subjects was tested by the method of Edwards. ${ }^{8}$

\section{Results}

Table 1 shows numbers and notification rates of the study malformations. The majority of each malformation (indeed the overwhelming majority of each except inguinal hernia) were reported as isolated conditions in liveborn singletons. Notification rates for liveborn singletons were far higher than for liveborn multiply-born boys for each malformation except inguinal hernia, where based on small numbers the rates were equal. The notification rate for each malformation was much higher in liveborn than in stillborn boys.

Tables 2-4 show relative risks of the malformations in liveborn singletons. The exact numbers of cases in these analyses varied according to the number of subjects with complete data for the variable under analysis, but for each analysis in the tables were at least $95.0 \%$ of the corresponding number in table 1 . Relative risks of cryptorchidism, inguinal hernia, and hypospadias decreased very significantly with increasing birthweight (table 2), as did allmalformations risks, while an opposite highly significant trend was present for hydrocoele. Risk of epispadias showed no significant relation to birthweight.

Risk of hypospadias increased very significantly with increasing maternal parity (table 3 ), but risks of the other genital tract malformations were not significantly related to parity. There was a statistically highly significant linear trend of risk of all-

Table 1 Numbers of notifications and notification rates, selected malformations in males, England and Wales.

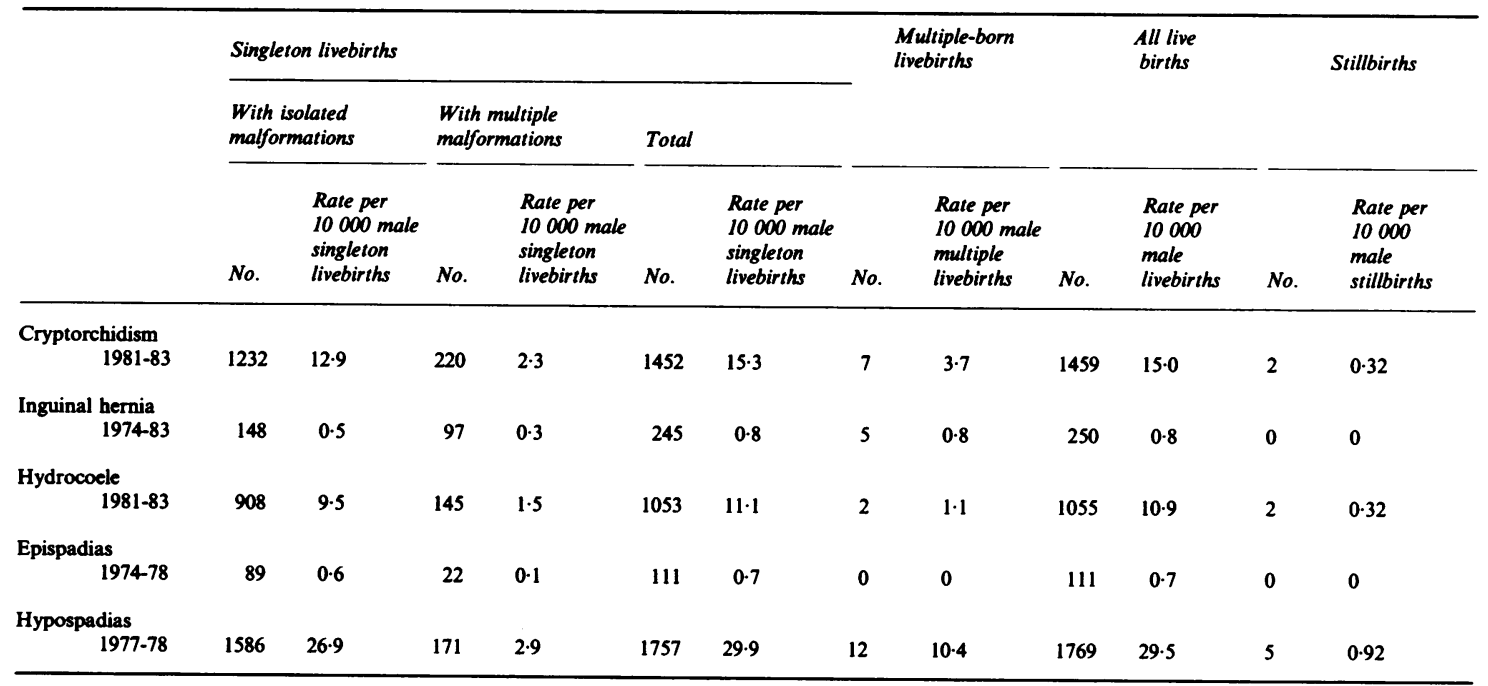


Table 2 Relative risks (and 95\% confidence limits) compared to other male singleton live births 1983, selected congenital malformations as solitary malformations in liveborn singleton males, by birthweight, England and Wales.

\begin{tabular}{|c|c|c|c|c|c|}
\hline \multirow{2}{*}{$\begin{array}{l}\text { Malformation and } \\
\text { years of data }\end{array}$} & \multicolumn{5}{|l|}{ Birthweight $(\mathrm{g})$} \\
\hline & $<2500$ & $2500-2999$ & $3000-3499$ & $3500-3999$ & $>4000$ \\
\hline $\begin{array}{r}\text { Cryptorchidism } \\
1981-83\end{array}$ & $1 \cdot 02(0 \cdot 79-1 \cdot 31)$ & $1 \cdot 37(1 \cdot 18-1 \cdot 59)$ & 1.00 & $0.82(0.71-0.95)$ & $0.65(0.52-0.81)^{*}$ \\
\hline $\begin{array}{r}\text { Inguinal hernia } \\
\qquad 1974-83\end{array}$ & $5.85(3.94-8.69)$ & $1.47(0.91-2.40)$ & 1.00 & $1.01(0.65-1.59)$ & $0.72(0.35-1.47)^{*}$ \\
\hline $\begin{array}{l}\text { Hydrocoele } \\
\qquad 1981-83\end{array}$ & $0.39(0.23-0.66)$ & $0.58(0.44-0.77)$ & 1.00 & $1.77(1.51-2 \cdot 07)$ & $2 \cdot 94(2 \cdot 48-3 \cdot 50)^{*}$ \\
\hline $\begin{array}{l}\text { Epispadiast } \\
\qquad 1974-78\end{array}$ & $0 \cdot 38(0 \cdot 10-1 \cdot 49)$ & $1.35(0.79-2.30)$ & 1.00 & $0.89(0.54-1.46)$ & $0 \cdot 45(0 \cdot 18-1 \cdot 12)$ \\
\hline $\begin{array}{r}\text { Hypospadias } \dagger \\
1977-78\end{array}$ & $1.70(1.41-2.04)$ & $1.47(1.29 \cdot 1 \cdot 68)$ & 1.00 & $0.88(0.77-1.00)$ & $0.79(0.65-0.95)^{*}$ \\
\hline $\begin{array}{c}\text { All malformations } \\
1977-83\end{array}$ & $2 \cdot 49(2 \cdot 44-2.54)$ & $1 \cdot 18(1 \cdot 16-1 \cdot 20)$ & 1.00 & $0.90(0.88-0.91)$ & $0.89(0.86-0.91)^{*}$ \\
\hline
\end{tabular}

- Linear trend significant at $p<0.001$

¥ Controls = all male singleton livebirths 1983 (data not available to derive control data for male singleton livebirths not notified as having the malformation under consideration).

† Cases = all malformations on OPCS files 1977-83 (1974-6 data not available); controls = other births 1983.

Table 3 Relative risks (and 95\% confidence limits) compared to other live births, selected congenital malformations as solitary malformations in liveborn singleton males, by maternal parity, $\uparrow$ England and Wales.

\begin{tabular}{|c|c|c|c|c|c|}
\hline \multirow{2}{*}{$\begin{array}{l}\text { Malformation and } \\
\text { years of data }\end{array}$} & \multicolumn{5}{|c|}{ Parity $\dagger$} \\
\hline & 0 & 1 & 2 & 3 & $>4$ \\
\hline $\begin{array}{l}\text { Cryptorchidism } \\
1981-83\end{array}$ & 1.00 & $0.99(0.87 .1 \cdot 12)$ & $0.91(0.76-1.08)$ & $0.91(0 \cdot 70-1 \cdot 18)$ & $0.76(0.53-1.09)$ \\
\hline $\begin{array}{l}\text { Inguinal hernia } \\
1974-83\end{array}$ & 1.00 & $0.86(0.59 .1 .24)$ & $0.58(0.33-1.02)$ & $1.48(0.82-2 \cdot 68)$ & $0.89(0.36-2 \cdot 21)$ \\
\hline $\begin{array}{l}\text { Hydrocoele } \\
\qquad 1981-83\end{array}$ & 1.00 & $0.91(0.78-1.06)$ & $0.98(0.80-1 \cdot 19)$ & $0.71(0.51-1.01)$ & $1.29(0.93-1.79)$ \\
\hline $\begin{array}{l}\text { Epispadias } \\
\qquad 1974-78\end{array}$ & 1.00 & $0.85(0.53-1.37)$ & $0.72(0.36-1 \cdot 45)$ & $1 \cdot 19(0 \cdot 50-2 \cdot 81)$ & $1 \cdot 15(0 \cdot 41-3 \cdot 22)$ \\
\hline $\begin{array}{l}\text { Hypospadias } \\
\qquad 1977-78\end{array}$ & 1.00 & $0.88(0.78-0.99)$ & $1.02(0 \cdot 87-1 \cdot 18)$ & $1 \cdot 32(1 \cdot 08-1 \cdot 62)$ & $1.56(1.25-1.97)^{*}$ \\
\hline $\begin{array}{c}\text { All malformations } \ddagger \\
1974-83\end{array}$ & 1.00 & $0.85(0.84-0.86)$ & $0.86(0.85-0.87)$ & $0.90(0.88-0.92)$ & $1.01(0.98-1.04)^{*}$ \\
\hline
\end{tabular}

- Linear trend significant at $p<0.001$

$\dagger$ Previous live and stillbirths for cases, but, because of data availability, previous live but not stillbirths for controls.

$\ddagger$ Cases $=$ all malformations on OPCS files 1974-83; controls = other live births 1974-83.

malformations across the range of parities in table 3, but this was based on very large numbers, without a substantial gradient.

The relative risk of each study malformation, and of all-malformations, was lower for secondborn than for firstborn boys; for hypospadias and for allmalformations, this was significant and in opposition to an otherwise consistent trend.

Highly significant trends of decreasing risk with increasing mother's age were found for hypospadias and for epispadias (table 4), and a highly significant trend in the opposite direction was present for hydrocoele.

None of the significant trends in risk of study malformations with maternal age and with parity was reduced by stratification by parity or maternal age respectively.

There were insufficient subjects in the subgroups of cases other than solitary malformations in liveborn singletons to analyse risks separately in these groups, 
Table 4 Relative risks (and 95\% confidence limits) compared to other male live births, selected congenital malformations as solitary malformations in liveborn singleton males, by maternal age, England and Wales.

\begin{tabular}{|c|c|c|c|c|c|}
\hline \multirow{2}{*}{$\begin{array}{l}\text { Malformation and } \\
\text { years of data }\end{array}$} & \multicolumn{5}{|c|}{ Maternal age (years) } \\
\hline & $<20$ & $20-24$ & $25-29$ & $30-34$ & $>35$ \\
\hline $\begin{array}{r}\text { Cryptorchidism } \\
\text { 1981-83 }\end{array}$ & $1.03(0.83-1.27)$ & $0.94(0.81-1.09)$ & 1.00 & $1.03(0.87-1 \cdot 20)$ & $1.09(0 \cdot 87-1 \cdot 37)$ \\
\hline $\begin{array}{l}\text { Inguinal hernia } \\
1974-83\end{array}$ & $1 \cdot 14(0.64-2.03)$ & $1.05(0 \cdot 70-1 \cdot 58)$ & 1.00 & $0.97(0.59-1.58)$ & $1 \cdot 75(0 \cdot 99-3 \cdot 10)$ \\
\hline $\begin{array}{l}\text { Hydrocoele } \\
\qquad 1981-83\end{array}$ & $0.91(0.71-1 \cdot 18)$ & $0.82(0.69-0.98)$ & $1 \cdot 00$ & $1 \cdot 05(0 \cdot 88-1 \cdot 26)$ & $1.31(1.03-1.67)^{* *}$ \\
\hline $\begin{array}{l}\text { Epispadias } \\
\qquad 1974-78\end{array}$ & $1 \cdot 72(0 \cdot 94-3 \cdot 15)$ & $1 \cdot 10(0 \cdot 67-1 \cdot 81)$ & 1.00 & $0 \cdot 78(0 \cdot 40-1 \cdot 55)$ & $0.20(0.03-1 \cdot 20)^{*}$ \\
\hline $\begin{array}{l}\text { Hypospadias } \\
1977-78\end{array}$ & $1 \cdot 40(1 \cdot 19-1 \cdot 65)$ & $1 \cdot 22(1 \cdot 08-1 \cdot 38)$ & 1.00 & $0.92(0.79-1.07)$ & $0.99(0.78-1.25)^{* *}$ \\
\hline $\begin{array}{c}\text { All malformations } \dagger \\
1974-83\end{array}$ & $1 \cdot 13(1 \cdot 10-1 \cdot 15)$ & $1.06(1.04-1.07)$ & 1.00 & $1.01(1.00-1.03)$ & $1 \cdot 20(1 \cdot 18-1 \cdot 23)$ \\
\hline
\end{tabular}

- Linear trend significant at $p<0.01$

** Linear trend significant at $\mathrm{p}<\mathrm{p0} .001$

$\dagger$ Cases = all malformations on OPCS files 1974-83; controls = other male livebirths 1974-83.

but an all-cases analysis (ie, including all subgroups) gave results which were similar to those in tables $2-4$ and in which the same trends were significant (although sometimes at higher or lower significance levels).

There was not significant or near-significant harmonic variation in month of birth for any of the malformations.

\section{Discussion}

Comparison with other published data for white populations suggests that some of the study malformations were greatly undernotified to OPCS, and hence that there was great potential for bias. The OPCS notification rate for cryptorchidism (1.5 per 1000 male livebirths) was about one tenth or less of that reported in ad hoc studies in whites, ${ }^{9-11}$ and that for inguinal hernia ( 0.08 per 1000 male livebirths) was less than $1 \%$ of rates found previously by various methods in white males. ${ }^{12-14}$ Given the difficulty of diagnosis of cryptorchidism in neonates, there may well also have been a substantial false positive rate within the OPCS cases. Hypospadias, however, appears to have been better notified: the OPCS notification rate (2.95 per 1000 male livebirths) was well within the range of published rates in whites; ${ }^{11} 15-19$ also, Knox et al, ${ }^{3}$ in a local comparison of OPCS data with a register in Birmingham, found that malformations of external genitalia (mainly hypospadias) had a sensitivity of $75 \%$ and a false positive rate of $14 \%$.

Particular undernotification to OPCS may well have occurred for multiply-born boys; notification rates of each malformation except inguinal hernia were far lower in the multiply-born than in singletons, and inguinal hernia notifications did not show the excess risk in multiply-born boys that has been reported in the literature ${ }^{1420}$ (although numbers of cases were small). The low OPCS notification rates for stillborn boys may well also have been due to undernotification.

Some of the significant associations with risk factors found in the study are in line with expectations from the literature, but others are not, and suggest possible bias for which the undernotification noted above gives considerable scope. Thus, although the OPCS data, like most previous work, showed associations of cryptorchidism in neonates, ${ }^{21}$ hypospadias ${ }^{1622-25}$ (although one study ${ }^{15}$ found otherwise), and inguinal hernia $^{121420}$ with low birthweight, the degree of increased risk of cryptorchidism in boys of under $2500 \mathrm{~g}$ was far less than that shown by careful clinical study, ${ }^{21}$ and the risk of hypospadias in those of low birthweight was also appreciably lower than in most previous studies. ${ }^{1622-25}$ There do not appear to be previous publications with which to compare the significant relation of hydrocoele to birthweight found here.

The smaller increased risks than in previous studies for cryptorchidism and hypospadias at low birthweight seem unlikely to be due to the method of selection of controls. They may well reflect biased undernotification of cases for which there are several potential mechanisms:

The monitoring scheme accepts only reports of 
malformations noted in the first seven days of life, but diagnoses of congenital malformations can occur later; Knox et $\mathrm{al}^{3}$ noted that failures of notification of hypospadias and epispadias in Birmingham to the OPCS scheme were mainly cases diagnosed after birth. Failures of notification to OPCS because of diagnosis after seven days might well be more common in very small babies for whom diagnosis may be more difficult.

Reporting of a malformation may be influenced by an expectation that the condition will correct itself. This may well have applied particularly to cryptorchidism and hydrocoele and, for cryptorchidism at least, may have been biased by birthweight since postnatal spontaneous descent of cryptorchid testes occurs more frequently in low than in high birthweight babies. ${ }^{1026}$

A malformation might not be reported because it was felt to be trivial. This would probably occur particularly in very ill babies, including babies of low birthweight needing intensive care, and thus might be biased by birthweight. Apparent triviality of the malformations compared to other medical issues about the individual might also explain the apparent poorer reporting of the study malformations in multiply-born babies than in singletons, and in stillborn than in liveborn.

The significant increase in risk of hypospadias with increasing maternal parity in the OPCS data was also at variance with previous studies, which have found greatest risk in sons of low parity mothers, ${ }^{22} 2427$ or no relation of parity to risk. ${ }^{131625} \mathrm{~A}$ possible mechanism for case selection bias in the OPCS data could be that mothers who had previous sons might be more able than other mothers to notice, and thus to draw to medical attention, genital abnormalities in their neonatal son; the chance that a mother has a previous son would increase with increasing parity. The trend of increasing risk with increasing parity occurred also, although less strongly, for all-malformations. This might indicate that the potential reporting bias by parity was shared by many malformations (although not, apparently, by all of the study malformations). A minor contribution, but not the main reason, for the trend of risk with parity was a difference between the definition of parity for cases and for controls-for cases it included stillbirths, while for controls, because of data availability, it did not. The effect of this difference must have been small, however, since stillbirths accounted for only $\frac{1}{2}-1 \frac{1}{2} \%$ of births in England and Wales in the years of and shortly before the subjects' births. ${ }^{4}$

The greater relative risks of each study malformation, and of all-malformations, for firstborn than for secondborn offspring suggest another potential reporting bias: since mothers usually stay in hospital with their offspring much longer after their first birth than after subsequent births, firstborn babies are available much longer for examination and potential diagnosis by hospital staff.

The significant increase in risk of hypospadias with decreasing maternal age in the present data accords with one previous study $^{28}$ but not with the great majority of the literature, in which no substantial relation has been found. ${ }^{13152223252729}$ No significant trend of risk with maternal age was found for all-malformations, and there is no obvious mechanism for case selection bias to have given such a result by maternal age independent of parity. The method of selection of controls does not appear to have been responsible for the finding. There do not appear to be previous studies with which to compare the significant relations of epispadias and hydrocoele to maternal age.

The seasonality of birth month previously demonstrated for cryptorchidism ${ }^{30-31}$ and for hypospadias in some $212332-33$ but not all studies 162234 was not present in the current data. It is possible that undernotification of malformations to OPCS might vary by season, for example be worst at times of greatest workload or of staff holidays, and that this variation might obscure any true seasonality of birth month.

To summarise, in some but not all instances comparison of the OPCS results with the literature suggests case-selection bias, for which there are plausible potential mechanisms. Such bias might well also apply to other malformations showing similar characteristics to the study conditions: for example, there are many malformations which are usually detected after birth ${ }^{11}$ and therefore might show selection biases by birthweight and parity as discussed above. Until the potential biases have been explored directly, the study raises doubts about the value of the OPCS data for assessment of risk factors for malformations, particularly where on past evidence ${ }^{3}$ the data appear greatly incomplete. There must also be unease about the value of incomplete and possibly biased data for assessment of geographical distribution, detection of epidemics, and assessment of secular trends of malformations: although hypothetically an approximately constant level of undernotification could leave a satisfactory monitoring scheme, in practice gross undernotification might well vary by place and time, particularly if the mechanisms discussed above were of importance. The potential biases discussed here for the England and Wales data might apply also to other malformation reporting systems which share methodological features with the OPCS scheme, as many do. ${ }^{1}$ The extent of and the mechanisms for bias need direct investigation in the OPCS and other data 
sets, by comparison of the routine data with data collected by more complete and reliable methods.

The views expressed in this paper are the authors' and do not necessarily represent those of the institutions within which they work.

We thank Dr M R Alderson for helpful comments on a draft of this paper, Mr J B Werner for unpublished births data, and Mr P Towers for help with data extraction.

\section{References}

${ }^{1}$ International Clearinghouse for Births Defects Monitoring Systems. 1984 Annual report. Wellington, New Zealand: ICBDMS, 1986.

2 Office of Population Censuses and Surveys. Congenital malformation statistics notifications 1971-1980, England and Wales. Series MB3 no. 1. London: HMSO, 1983.

${ }^{3}$ Knox EG, Armstrong EH, Lancashire R. The quality of notification of congenital malformations. J Epidemiol Community Health 1984; 38: 296-305.

${ }^{4}$ Office of Population Census and Surveys. Birth statistics 1974-83 England and Wales. Series FM1 nos. 1-10. London: HMSO, 1977-85.

${ }^{5}$ Mantel N, Haenszel W. Statistical aspects of the analysis of data from retrospective studies of disease. J Natl Cancer Inst 1959; 22: 719-48.

${ }^{6}$ Meittinen OS. Estimability and estimation in casereferrent studies. Am J Epidemiol 1976; 103: 226-35.

${ }^{7}$ Mantel N. Chi-square tests with one degree of freedom: extensions of the Mantel-Haenszel procedure. J Am Stat Assoc 1963; 58: 690-700.

${ }^{8}$ Edwards JH. The recognition and estimation of cyclic trends. Ann Hum Genet Lond. 1961; 25: 83-6.

${ }^{9}$ Buemann B, Henriksen H, Villumsen AL, Westh A, Zachau-Christiansen B. Incidence of undescended testis in the newborn. Acta Chir Scand 1961; Suppl 283: 289-93.

${ }^{10}$ Scorer CG. The descent of the testis. Arch Dis Childh 1964; 39: 605-9.

11 Myrianthopoulos NC, Chung CS. Congenital malformations in singletons: Epidemiologic survey. Ed Bergsma D. Birth defects: Original Article Series Vol. X no. 11. New York: Stratton, 1974.

${ }^{12} \mathrm{Knox}$ G. The incidence of inguinal hernia in Newcastle children. Arch Dis Childh 1959; 34: 482-6.

13 Chung CS, Myrianthopoulos NC. Factors affecting risks of congenital malformations. 1. Epidemiologic analysis. Ed Bergsma D. Birth defects: Original Article Series Vol XI, no. 10. New York: Stratton, 1975.
${ }^{14}$ Czeizel A. Epidemiologic characteristics of congenital inguinal hernia. Helv Paediatr Acta 1980; 35: 57-67.

15 Roberts CJ, Lloyd S. Observations on the epidemiology of simple hypospadias. $\mathrm{Br} \mathrm{Med} J \mathrm{~J}$ 1973; 1: 768-70.

16 Sweet RA, Schrott HG, Kurland R, Culp OS. Study of the incidence of hypospadias in Rochester, Minnesota, 19401970 , and a case-control comparison of possible etiologic factors. Mayo Clin Proc 1974; 49: 52-8.

17 Svensson J. Male hypospadias, 625 cases. Associated malformations and possible etiological factors. Acta Paediatr Scand 1979; 68: 587-92.

18 Baird PA. Incidence of hypospadias. Lancet 1985; i: 1162.

19 Simpkin JM, Owens JR, Harris F. Incidence of hypospadias. Lancet 1985; ii: 384.

${ }^{20}$ Depue RH. Maternal and gestational factors affecting the risk of cryptorchidism and inguinal hernia. Int $J$ Epidemiol 1984; 13: 311-8.

${ }^{21}$ Scorer CG, Farrington GH. Congenital deformities of the testis and epididymis. London: Butterworths, 1971.

22 Chen YC, Woolley PV Jr. Genetic studies on hypospadias in males. $J$ Med Genet 1971; 8: 153-9.

23 Avellán L. On aetiological factors in hypospadias. Scand J Plast Reconstr Surg 1977; 11: 115-23.

${ }^{24}$ Heinonen OP, Slone D, Shapiro S. Birth defects and drugs in pregnancy. Littleton, Mass.: Publishing Sciences Group, 1977.

${ }^{25}$ Källén B, Winberg J. An epidemiological study of hypospadias in Sweden. Acta Paediatr Scand 1982; Suppl 293: 1-21.

${ }^{26}$ Villumsen AL, Zachau-Christiansen B. Spontaneous alterations in position of the testes. Arch Dis Childh 1966; 41: 198-200.

${ }^{27}$ Hay S, Barbano H. Independent effects of maternal age and birth order on the incidence of selected congenital malformations. Teratology 1972; 6: 271-9.

28 Büchi EC. Über die Abhängigkeit der Missbildungen vom Gebäralter. Arch Julius Klaus Stift Vererbungsforsch 1950; 25: 61. Cited by Avellán (ref 23).

${ }^{29}$ Ross JF, Farmer AW, Lindsay WK. Hypospadias. A review of 230 cases. Plast Reconstr Surg 1959; 24: 357-68.

30 Czeizel A, Erödi E, Tóth J. An epidemiological study on undescended testis. J Urol 1981; 126: 524-7.

31 Jackson MB, Swerdlow AJ. Seasonal variations in cryptorchidism. J Epidemiol Community Health 1986; 40: 210-3.

32 Theander G. Seasonal distribution of births of boys with anomalies of the urethra. Scand J Urol Nephrol 1970; 4: 1-5.

${ }^{33}$ Wehrung DA, Hay S. A study of seasonal incidence of congenital malformations in the United States. Br J Prev Soc Med 1970; 24: 24-32.

34 Aarskog D. Clinical and cytogenetic studies in hypospadias. Acta Paediatr Scand 1970; Suppl 203: 1-62. 